\title{
Funding and remuneration of interdisciplinary primary care teams in Canada: a conceptual framework and application
}

W. Dominika Wranik ${ }^{1 *}$ (D) Susan M. Haydt ${ }^{2}$, Alan Katz ${ }^{3}$, Adrian R. Levy ${ }^{4}$, Maryna Korchagina ${ }^{5}$, Jeanette M. Edwards ${ }^{6}$ and lan Bower ${ }^{7}$

\begin{abstract}
Background: Reliance on interdisciplinary teams in the delivery of primary care is on the rise. Funding bodies strive to design financial environments that support collaboration between providers. At present, the design of financial arrangements has been fragmented and not based on evidence. The root of the problem is a lack of systematic evidence demonstrating the superiority of any particular financial arrangement, or a solid understanding of options. In this study we develop a framework for the conceptualization and analysis of financial arrangements in interdisciplinary primary care teams.
\end{abstract}

Methods: We use qualitative data from three sources: (i) interviews with 19 primary care decision makers representing 215 clinics in three Canadian provinces, (ii) a research roundtable with 14 primary care decision makers and/or researchers, and (iii) policy documents. Transcripts from interviews and the roundtable were coded thematically and a framework synthesis approach was applied.

Results: Our conceptual framework differentiates between team level funding and provider level remuneration, and characterizes the interplay and consonance between them. Particularly the notions of hierarchy, segregation, and dependence of provider incomes, and the link between funding and team activities are introduced as new clarifying concepts, and their implications explored. The framework is applied to the analysis of collaboration incentives, which appear strongest when provider incomes are interdependent, funding is linked to the team as a whole, and accountability does not have multiple lines. Emergent implementation issues discussed by respondents include: (i) centrality of budget negotiations; (ii) approaches to patient rostering; (iii) unclear funding sources for space and equipment; and (iv) challenges with community engagement. The creation of patient rosters is perceived as a surprisingly contentious issue, and the challenges of funding for space and equipment remain unresolved.

Conclusions: The development and application of a conceptual framework is an important step to the systematic study of the best performing financial models in the context of interdisciplinary primary care. The identification of optimal financial arrangements must be contextualized in terms of feasibility and the implementation environment. In general, financial hierarchy, both overt and covert, is considered a barrier to collaboration.

\footnotetext{
* Correspondence: dwl@dal.ca

${ }^{1}$ School of Public Administration, Dalhousie University, Halifax, Canada

Full list of author information is available at the end of the article
} 


\section{Background}

Mature health systems are placing increased emphasis on Interdisciplinary Primary Care Teams (IDPC Teams) to deliver primary care [1]. This approach has been described as more appropriate in addressing the health needs of populations by creating more comprehensive care options and increasing continuity and coordination [2-6]. The financial structure of IDPC teams has been recognized as an important contributor to team functioning and therefore a key concern to policy makers in this area.

The Canadian health care system is publicly funded; close to $70 \%$ of all health expenditures are tax financed [7]. The system is governed by a national Canada Health Act, which stipulates the broad conditions that Provinces/ Territories must comply with in order to qualify for federal budget transfers. The specifics of health care budget allocation are resolved at the level of the Provinces/Territories. In many cases, especially at the primary care level, delivery of services is by private providers. This results in a set of 13 similar, yet unique health systems in Canada, making it an interesting case study from the international perspective.

Primary care physicians are gatekeepers to the health care system; patients typically cannot access specialist services without a prior primary care consultation. Primary care physician services are covered by the public insurance system, meaning patients do not face out of pocket payments for services that are defined as "medically necessary". The Canada Health Act requires coverage for services delivered by physicians, but coverage of services provided by other primary care providers is optional. Therefore there is no mechanism to ensure a unified national approach to the funding of IDPC teams or remuneration of providers within these teams.

Approximately half of all physicians are generalists/ family physicians [8]. On average, family physicians report billing $32.3 \%$ of their incomes from fee-for-service (FFS), 6.3\% from salaries, $4.9 \%$ from sessional rates, $45.9 \%$ from blended models, and $10.6 \%$ from other remuneration methods [9].

Primary care reform in Canada has been ongoing over the past 16 years, with a large system-wide impetus in 2000 and 2006, when the Federal government provided support to Provinces/ Territories to redesign the delivery of primary care through the Primary Care Transition Fund [7]. This was operationalized differently across regions in how IDPC teams were designed and implemented $[10,11]$. Some provinces, such as Alberta and Ontario, introduced system wide policy frameworks to which primary care providers were invited to adhere [12] - a top-down approach. Other provinces, such as Nova Scotia, introduced policies in response to existing changes in front-line delivery-a bottom-up approach. The resultant financial models are the focus of this study.

Using primary qualitative interview data, as well as secondary online data-sources from three Canadian Provinces we develop a conceptual framework of funding and remuneration models in the IDPC team setting. We apply the framework to the analysis of incentives created, expected impacts on collaboration, and the assessment of optimal financial models in a variety of contexts. Finally, we discuss issues associated with the implementation of optimal models on the basis of qualitative data from a research roundtable discussion.

\section{Literature}

Literature focused on IDPC teams typically omits discussion of funding and remuneration methods, except to mention their importance. For more than four decades, the emphasis has been on how team-based care can offer solutions to system problems such as a growing patient population and shortages of trained personnel [13]. It has been argued that well-functioning teams, when compared to typical sole profession practices, appear to have a number of advantages. IDPC Teams can create conditions for improved health outcomes, improved clinical performance, higher quality of care, and improved chronic disease management [2-6, 14-20]. IDPC teams may be preferred by patients $[3-5,21]$, and by providers [3, 4, 6, 18, 22, 23]. Lastly, some suggest improvements in system level outcomes, such as efficiency of resource use and reduced fragmentation [3, 5, 6, 23, 24].

Studies have also focused on identifying a number of organizational factors that influence the functioning of IDPC teams. Facilitators of team functioning described in the literature include supportive, clear and transparent processes, institutional reinforcements, and a more elusive sense of togetherness [4, 6, 15, 18, 22, 23, 25-31]. Barriers to team functioning described in the literature include insufficient education and training, the mismanagement of resources and team diversity (e.g. creation of silos or imbalanced power relationships or pay status between providers) and miscommunication [15, 26-28, 30, 32-37].

However, the literature is mostly silent on the description or effects of financing models for IDPC teams, aside from indicating that these are important [38-40]. The design of funding and remuneration models remains understudied in terms of options and impact on team functioning. Financing is considered important, with very little analysis or discussion of optimal methods [41].

There is a lack of descriptive, comparative or evaluative studies of various approaches to the funding of teams and remuneration of providers within the primary care context. Several studies focus on the health care outcomes under the different care models with varying remuneration methods for physicians in Canada [42-46]. One 
draws a distinction between practice and provider level financial incentives, but not the interaction between them [47]. One conceptual framework provides a broad overview of incentives created by various remuneration and funding mechanisms at the provider or the organization level, and their ability to support a variety of policy goals, but does not discuss the interactions between various levels of incentives [24]. While a large strand of literature has focused on the remuneration of individual providers (examples of systematic reviews include [48-51]), this is generally not addressed at the team level. Some observe that the variety of remuneration methods within teams stand in the way of effective team practice [52]. Few studies incorporate a discussion about the remuneration of non-physician providers $[1,53]$. In the majority of literature the issues of interplay between team funding and provider remuneration, and between remuneration of physician and non-physician providers are ignored. Our study partially fills these gaps by providing a conceptual framework that facilitates analysis of approaches to team financing; the framework is applied to approaches used in three Canadian provinces, with focus on incentives for collaboration between providers.

\section{Methods}

\section{Study design}

This is a qualitative study using semi-structured interviews, a research roundtable discussion, and a document review. Data collection was conducted between January 2014 and October 2014. The study protocol was approved by the research ethics committees at nine district health authorities in Nova Scotia, at the University of Manitoba, and at Alberta Health. The study protocol and reporting followed the COREQ guidelines (see Additional file 1).

The study was conducted using an integrated knowledge translation approach, which relies on the continuous involvement of stakeholders is all stages of the research process. The research team included policy decision makers from each of the three Provinces, who shaped the research questions, facilitated data collection, provided data, and participated in analysis and interpretation.

\section{Sampling}

We relied on purposive sampling to recruit leaders overseeing IDPC Teams, such as executive directors, directors, and/or managers (titles varied by Province). In Nova Scotia, respondents were at the health authority level and oversaw more than one clinic. In Alberta, we interviewed executive directors of Primary Care Networks of varying sizes, most with multiple clinics, including one or more sites. In Manitoba, we interviewed primarily managers of individual clinics. Potential respondents were identified by the Department of Health and Wellness in Nova Scotia, by the Ministry of Health in Manitoba, and by an online search for contacts of Primary Care Networks in Alberta. For the Research Roundtable, we invited policy decisionmakers from the three Provinces, as well as one to two interview respondents from each province.

\section{Data collection and analysis}

The descriptive component of our study was developed using online policy documents across Canada (see Appendix), academic studies and qualitative interviews. The evaluative component relied on the qualitative interviews, as well as a research roundtable. Specifically, the document review aimed at describing the types of IDPC Teams across Canada, the interviews aimed at the assessment of merits and demerits of various options, and the research roundtable aimed at the discussion of implementation issues. Given the qualitative nature of the study, interview respondents and roundtable participants were able to address all issues (description, assessment, and implementation) at their discretion.

Semi-structured qualitative interviews (Additional file 2) were held between January and May 2014 with 19 respondents, who represented six PCNs in Alberta, eight clinics in Manitoba, and five district health authorities in Nova Scotia (four at the regional level, and one discussing four individual clinics separately). Qualitative data related to the description of the structure of teams were analyzed using a framework synthesis approach [54], which was structured around the a priori framework that had also guided data collection (Additional file 3). Qualitative data related to the assessment of strengths and weaknesses and implementation issues were analysed using a grounded theory approach $[55,56]$, with focus on emergent themes not already covered by the a priori framework.

Qualitative components of interview responses were organized into a matrix. Responses within individual matrix elements were coded and synthesized (goals, logistics, organization, etc.). The factual information within the matrix was supplemented with/corroborated by data from the document reviews. In addition, respondents completed a table outlining the composition of their team and the method of payment offered to types of providers. Data identifying team composition, remuneration method, funding source were compiled into a table to support the framework synthesis approach (Additional file 3).

The research roundtable took place on October 27/28, 2014 at Dalhousie University in Halifax, Nova Scotia (Additional file 4). The roundtable had 14 participants, of which four are co-authors of the paper, five had previously participated as an interview respondent, and five were new to the study. Participants discussed a draft framework, extant financial models in the three provinces, their strengths and weaknesses with emphasis 
on creating collaboration incentives, and implementation issues as perceived by policy makers versus managers of teams. The roundtable was transcribed and coded. Thematic analysis was used to analyse the transcriptions.

Iteratively, to guide us during data collection and as a result of data analysis, an analytical and conceptual framework was developed $[57,58]$. The framework consists of two elements, a spectrum of funding models, and a typology of nine distinct types of team funding. Both are described in detail in the results section. The purpose of the framework was to analyze the qualitative data in this study, conceptualize funding approaches in a more general sense, and support the collection and analysis of further empirical data.

\section{Results and discussion}

\section{Characteristics of teams described by respondents}

Profiles of teams described by interview respondents are summarized in Table 1. Participating Primary Care Networks in Alberta ranged from one to 86 clinics, and between 2 and 385 physicians, 3 to 55 nurses, and 1 to 39 other providers. In each case, the PCN receives funding through Alberta Health to pay non-physician and non-clinical staff. The funding amount is based on the patient numbers of individual physicians. Physicians bill on a FFS basis from a separate funding channel. Respondents in Manitoba each described one clinic/ team with a membership of 1 to 28 physicians, 1 to 9 nurses, and 1 to 43 other providers. Physicians in Manitoba bill FFS from the Department of Health, or receive salaries from the Health Authority, or a mix of these two. The predominant method of remuneration of other providers is salary. Respondents in Nova Scotia described between 1 and 8 clinics, consisting of 1 to 12 physicians, 2 to 10 nurses, and 3 to 6 other providers. In the clinics described here, physicians in Nova Scotia receive salaries through an alternative funding plan from the Department of Health, and other providers receive salaries from the Health Authority.

\section{Defining the interdisciplinary primary care team}

Sixteen respondents indicated that the interdisciplinary primary care team brings together different healthcare providers or health professionals who work together. Nine explicitly stated that the care is organized around the patients' or clients' needs, and five indicated that an IDPC team serves the same client population (patient panel or roster). In addition, respondents mentioned shared goals, communication, co-location, and comprehensive and seamless care. For the purposes of this study, we define "collaboration" to encompass the working together of different health professionals to achieve shared goals [59]. Respondents described IDPC teams as centered on client needs, and one respondent characterized the physician as the core of the team.

\section{"Different health professionals of different disciplines working together to better serve the client." \\ "... number of allied health workers who are working alongside the physician...".}

\section{Goals of the interdisciplinary primary care team}

Goals described by interview respondents fell into three categories: (i) care for particular conditions; (ii) achievement of health system goals; and (iii) workplace improvement. For example, respondents discussed the management and self-management of chronic conditions, provision of targeted services such as obstetrics, HIV care, sexual health, improvements in access for patients or work-life balance for providers, and other goals.

\section{Spectrum of financial hierarchy and financial integration} (conceptual framework)

The profiles of the funding and remuneration approaches described by respondents are captured in Table 1 . Based on the descriptions of the funding models by interview respondents, we propose a spectrum of the degree of financial hierarchy and financial integration within teams/ networks (Fig. 1). On the basis of interviews, we identify these as two core aspects to characterize Weberian ideal types of financial models $[57,58]$. The spectrum allows for a discussion of observed models and the extent to which they approach one of the ideal types.

Financial hierarchy refers to the degree to which incomes of some providers depend on the activities of other providers, in other words the focus is on hierarchy that is created by financial arrangements. Financial integration is the extent to which remuneration sources and resultant accountability flows are streamlined. To facilitate discussion, four discrete types in the continuum are proposed, the two extreme ends of the spectrum, and two intermediate types.

The traditional model of primary practice in the Canadian FFS environment is captured in Type 1. A physician (MD) receives FFS payments from the Ministry of Health and can, at their discretion, employ additional health care providers (HCP). At the opposite of the spectrum lies the integrated non-hierarchical model with equivalent providers, labelled Type 4. One payer allocates a block grant to a primary care team entity (clinic, network, denoted with a yellow oval), who distributes the payments to individual health care providers, including the physician. Community Health Centres across Canada most closely resemble this type (http://www.cachc.ca/). 


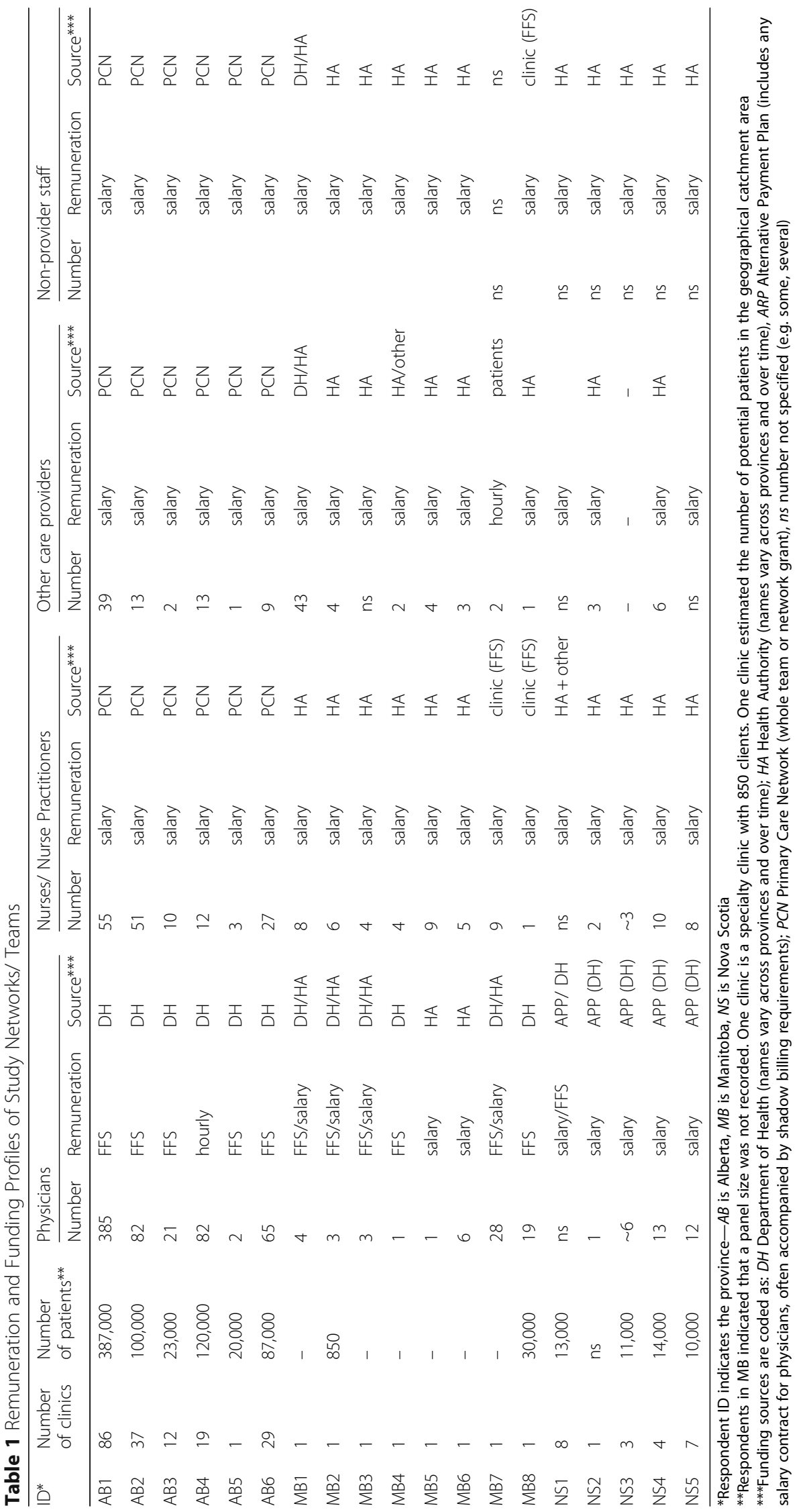




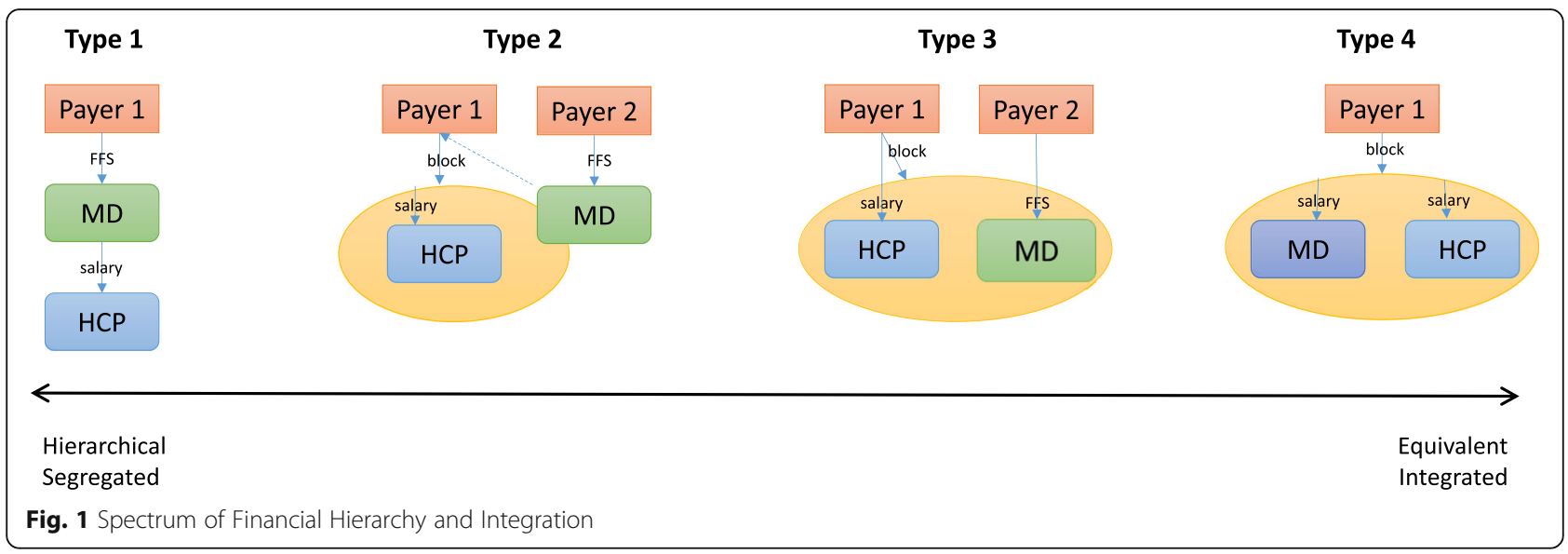

Type 2 captures a covert hierarchy: a block grant offered to the team entity is based on the activities of the physician. The physician receives FFS payments from the same or a second payer, whereas other health care providers receive salaries from the team entity. A financial hierarchy is maintained due to the dependence of non-physician provider incomes on the activities of the physician. Type 2 fits the financial arrangements in most Primary Care Networks in Alberta, and several of the responding clinics in Manitoba.

For example, PCNs in Alberta receive a capitation payment. The associated patient roster is established on the basis of patient visits to physicians who are members of the PCN. In addition, physicians continue to bill FFS. Therefore, at the core of the funding amount to the $\mathrm{PCN}$ is the physician-patient interaction, even though a block fund is transferred to the PCN. A similar dynamic is observed in several clinics in Manitoba, where funding to the team is tied to the physicians' activities and/or patient roster, or funded directly by the physicians' FFS billings. This model was criticized by many respondents as one prioritizing physician activities and creating a dependency of all incomes on the activities of physicians, which could impede team practice. For example, there is a reluctance to delegate patients to non-physician providers as this reduces the capacity for fee-for-services billing. There is also an incentive for physicians to participate in patient visits with other providers where such participation is not necessary from the clinical perspective. Physicians were also described as being in charge, even if not officially, for example:

"... Even though the PCN will pay the salary and put in a highly skilled person into an office, there's pushback on that because of the risk of [the physician] not being able to charge for that patient appointment ...".
The multiplicity of funding sources adds further complications, such as multiple lines of accountability within what is thought to be one organization, and differential amounts of payment for similar tasks. As noted by one respondent:

\section{"I have multiple funding sources. [...] I am left sometimes with the perception that some people are getting paid a lot for the care that they provide versus perhaps what the physician might provide ..." [for the same payment].}

Further toward the east end of the spectrum lies Type 3, a non-hierarchical model that retains segregation of providers through multiple funding sources. Primary Care Teams in Nova Scotia are examples of this type-an equivalent but segregated model. Funding of other providers and/or the team is not related to the activities of the physician, but physicians' and other providers' remuneration is drawn from different sources (e.g. health ministry versus health authority). Some teams receive block transfers, and in several instances these originate with different sources (e.g. health ministry, pharmaceutical company, special programs through another ministry, etc.) with competing priorities. The lines of accountability become blurred. Respondents noted:

"... there's a big challenge there for physicians in understanding that they're a part of a bigger system that sometimes they don't have control over, and sometimes none of us have any control over."

"... we don't have direct control over how these clinicians work in our model, so that's a challenge ...",

“...They work their hours, they're paid their salary, but there's no control over their output, as you say, how do you get that output?". 
The reluctance to relinquish control on the part of physicians is in part justified in that decisions about care can be delayed through a team or organizational approach:

“... physicians generally shun the formal governance world ... if a decision needs to be made, they just make it and away we go, versus having to wade through a number of levels of decision-making and waiting for approvals ...".

In situations where physicians continue to receive FFS remuneration, and not salaries, respondents observed barriers to delegation:

"... physicians don't want her [practice nurse] doing them [services] because then that's taking money out of their pocket ...".

The environment for collaboration is also impeded when providers have different employment benefits due to multiple funders and funding sources:

"The only thing is that docs have a totally separate contract. So they come in at a different vacation rate [...] why do the docs start with 4 weeks' vacation and everyone else starts at 3? ...".

The FFS model was further seen as a barrier to collaboration mediated by the lack of space:

“... so if you're strictly fee-for-service, and then we're trying to put a nurse in one of your exam rooms, so now you're down one exam room, you know, you've just cut your patient load for that day in half ...".

It should be noted that remuneration was not necessarily considered as the core motivator for providers, for example respondents noted:

\section{"If you are looking for financial remuneration for doing the work, this is not the organization for you." \\ "... so it's not all driven by who pays and who is responsible for the policy of that person ...".}

\section{Typology of financial models (conceptual framework)}

The spectrum of financial segregation/ integration is further disentangled with a typology $[57,58,60]$ and its application to a discussion of potential incentive effects on collaboration. Respondents (interviews and roundtable) agreed that collaboration was an important interim outcome, even though patient outcomes would be of ultimate interest. The alignment of incentive effects has been mentioned as important [38-40], but has not been unpacked in detail.

The typology defines two dimensions of the financial model: (i) funding - the financial compensation of the team as an entity (and degree to which this is isolated from remuneration), and (ii) remuneration-the financial compensation of providers within teams (and degree to which their incomes are dependent). Each dimension has three categories. Each type is a combination of one funding category and one remuneration category. This allows for a discussion of impact of the interplay between funding and remuneration on, for example, collaboration, to which the typology is applied in the present study.

Approaches to funding are categorized by the extent to which they are linked to the activities of the team: (i) funding that is directly pegged to the activities of the team as a whole (e.g. number of services provided by the team, number of patients serviced by the team); (ii) funding that is not linked to activities (e.g. block grants based on a geographical roster or budget priorities); and (iii) funding that is directly pegged to the activities of a core provider (e.g. a FFS payment to the physician). Approaches to remuneration are categorized by the degree of dependence between provider incomes: (i) interdependence (incomes of providers depend on the activities of other providers to the same degree, e.g. providers receive a fixed share of an activity based team fund); (ii) independence (incomes of providers are not linked to each other, e.g. all receive a fixed salary); and (iii) hierarchical dependence (incomes of some providers depend on the activities of a core provider, but not vice versa, e.g. the FFS revenue of a physician is used to pay salaries of the nurses). Eight plausible model types emerge; an example of each is provided in Table 2.

The typology can serve as an analytical tool for assessing the performance of financial models along a number of criteria, and can serve as a framework to guide the collection of further empirical data. As an example, incentives for collaboration are greatest in the top left cell, which corresponds to Type 4 in the spectrum, and lowest in the bottom right cell, which corresponds to Type 1. Each provider is motivated to collaborate with others, when the reward is tied to the performance of the whole team. Furthermore, as discussed in the previous section, a financial hierarchy discourages collaboration.

The typology allows for a discussion of optimal financial arrangements in the presence of contextual constraints. For example, in a rural setting in Canada, a patient roster would have to be geographical. The typology illustrates that this incentive neutral funding category can be coupled with an interdependence in 
Table 2 Typology of Financial Models*

\begin{tabular}{|c|c|c|c|c|c|}
\hline & & & $\begin{array}{l}\text { Remuneration to Provid } \\
\text { (Type of dependence b } \\
\end{array}$ & ween provider income & \\
\hline & & & Interdependence & Independence & Hierarchical dependence \\
\hline & & Impact on Collaboration & Positive & Neutral & Negative \\
\hline $\begin{array}{l}\text { Funding to teams } \\
\text { (funding base) }\end{array}$ & $\begin{array}{l}\text { Linked to the activities } \\
\text { of the whole team }\end{array}$ & Positive & $\begin{array}{l}\text { Patient rostered to } \\
\text { team, providers receive } \\
\text { a fixed share. }\end{array}$ & $\begin{array}{l}\text { Patients rostered to } \\
\text { team, providers } \\
\text { receive fixed salaries. }\end{array}$ & $\begin{array}{l}\text { Patient attached to } \\
\text { team, P4P to individual } \\
\text { providers. }\end{array}$ \\
\hline & $\begin{array}{l}\text { Delinked from provider } \\
\text { activities }\end{array}$ & Neutral & $\begin{array}{l}\text { Geographical roster, } \\
\text { providers receive fixed } \\
\text { share. }\end{array}$ & $\begin{array}{l}\text { Geographical roster, } \\
\text { providers receive } \\
\text { fixed salaries. }\end{array}$ & $\begin{array}{l}\text { Geographical roster, P4P } \\
\text { to individual providers. }\end{array}$ \\
\hline & $\begin{array}{l}\text { Linked to the activities } \\
\text { of one provider }\end{array}$ & Negative & Not possible. & $\begin{array}{l}\text { Patients rostered to } \\
\text { physician, providers } \\
\text { receive fixed salaries } \\
\text { from team. }\end{array}$ & $\begin{array}{l}\text { Patients rostered to } \\
\text { physician, physician } \\
\text { pays others. }\end{array}$ \\
\hline
\end{tabular}

* Cells provide examples, not an exhaustive list

remuneration to optimize the model type. It also highlights that the interplay between funding at the team level and remuneration of providers must be taken into account.

\section{Emergent implementation issues}

Implementation issues were discussed primarily during the roundtable, but were also addressed by respondents during qualitative interviews. They are issues identified as important to consider during the implementation of a selected funding/ remuneration model. Four core issues emerged from the thematic analysis of qualitative roundtable and interview data: (i) budget negotiations; (ii) rostering of patients; (iii) funding for space and equipment; and (iv) community engagement.

First, the negotiations of budgets include decisions regarding the mix of providers and services, as well as the budget base (services or resources based). Provincial ministry representatives noted that evidence is insufficient with respect to the optimal mix of providers or services, and decisions were often based on convention or convenience. Team managers, some of whom were also providers, thought that the distance between budget negotiations and the front-line of care provision was inversely related to the ability for teams to respond to patient/community needs. They noted a disagreement between ministries and managers, where ministries would prefer ex ante planning of services based on evidence, and managers/ providers would prefer flexibility and the ability to adjust services to emergent needs of the patient population, facilitated by a resources based budget.

Second, the question of patient rosters proved surprisingly contentious. Terminology varied across provinces, from roster, to panel, to patient list and patient attachment. Some saw the roster as a suitable tool for the funder to influence services by defining targeted roster sizes per physician:
"... all the patients in our collaborative practice are rostered to a doctor and the clinic and full time physicians are expected to have a minimum panel of 1350 patients ...".

Others perceived the roster as a negative topic:

"... panel management within the province [...] has been a contentious issue with physicians in the province ..."

"... [we are] very familiar with the administrative difficulties of looking at panels but more importantly, we also have the fundamental belief that this should be a patient decision" [referring to the choice of doctor].

From the perspective of the financial model, a patient roster is necessary for any component of funding or remuneration to be capitation. For example, for a team as an entity to receive block funding, the size of its patient population must be defined. This presents a challenge, when the development of patient rosters is politically not desirable, yet the hesitations are not clearly articulated. It is also a challenge, when the funding model requires that patients be rostered to physicians, which preserves a hierarchy. Furthermore, respondents observed that physicians would "drop-in" on visits with other providers to fill the requirement of the specific patient roster model.

Third, roundtable participants discussed the problem of funding for space and equipment. Approaches to this issue varied widely across participating sites, from the physician as owner of the clinic structure, to ad hoc solutions such as space sharing with a community centre, or emergency room, and having no financial support for space. For example:

"...physicians own their clinics ... we pay a very small amount of space within their clinic ..."; 
"and the building, the space, the EMR are all funded through the district, ... exam tables, you name it ... the docs come and they pay us [...] just to sit down and work ..."

"... clinic space is actually what used to be a community hospital and now it is partially a collaborative practice clinic and partially a [...] long term care facility ..."

"there's the touchy point is that no, we actually don't provide any compensation". [for space]

Fourth, a desire to be responsive to community needs, and/or engage communities and patients in care planning and processes was discussed. One participant noted about community engagement "That's the dream, that's what I want." Approaches to community engagement ranged from inclusion of patients in care decisions to engaging patients in formal planning processes.

"... engaging the patient as part of their care and seeing them as part of the team ..."

"... what our community health boards are meant to do [...] [is] ask the public that they serve what they need ..",

"There is a patient in the health authority [...]

[engaged] on a policy level ...".

Respondents noted an emerging conflict around the issue of decision-making. Increasingly, it appeared that health authorities strive to be the decision-makers, and governments are pushing for standardization of care. This was perceived as being in conflict with the concurrent general push to involve communities and patient populations in the care-planning processes. Respondents identified these as contradictory forces, and noted emerging contradictory lines of accountability to the funder, to the patients and to the community.

\section{Conclusions}

The goal of our paper is to create a conceptual framework for the study of financial arrangements in IDPC teams. The framework consists of a typology of provider remuneration methods, and team funding models. The framework is applied to the discussion of financial incentives for collaboration that are created in three Canadian provinces, the desirability of particular financial arrangements relative to others, and the implementation issues identified by managers and decision-makers. Consequently, our results are twofold; we provide the conceptual framework, and we provide qualitative evidence of the implications of particular financial arrangements on collaboration.
Our study indicates that incentives are strongest, when provider remuneration is interdependent and combined with a team funding model that is linked to whole team activities. The conceptually optimal arrangement must align with the context to which it is applied, however, and important implementation issues need to be considered. For example, a clear patient roster is required, which may not be feasible for political or other reasons. Furthermore, we know that non-financial incentives play an important role in motivating providers. An exploration of the interplay between financial and nonfinancial incentives would be an interesting follow-up study.

It is clear that a financial hierarchy impedes the collaboration function of an IDPC team. Removal of the direct hierarchy between two types of providers, however, is not sufficient. Hierarchy continues to be seen as a challenge in situations where team funding is tied to physician activities. Furthermore, an additional challenge is created through a multiplicity of funding sources that results in multiple lines of accountability. In many examples, the current financial arrangements define the physician as distinct, and often more important than other providers.

A clear conceptual framework is an important step in the building of a systematic evidence base for the design of financial models in the IDPC context. It facilitates data collection for further qualitative and quantitative studies, and provides a reference point for the discussion and comparison of results.

\section{Appendix}

\section{Policy Documents}

Manitoba Health, Healthy Living and Seniors. My Health Teams; Key Elements. Accessed online: http:// www.gov.mb.ca/health/primarycare/public/myhts/elem ents.html.

Government of Saskatchewan. 2012. Patient centered community designed team delivery. A framework for achieving a high performing primary health care system in Saskatchewan.

Patient Centred. (2012). Primary Health Care Frame work Report. Retrieved online at: http://www.health. gov.sk.ca/phc-framework-report.

Saskatchewan Medical Association. (2014). Primary Health Care Team Composition. Retrieved online at: http://www.sma.sk.ca/utility/28/primary-health-care-

framework.html

Ontario Ministry of Health and Long Term Care. (2009). Family Health Teams: Advancing Family Health Care a Guide to Physcian Compensation. Toronto: Ontario Ministry of Health and Long Term Care.

Ontario Ministry of Health and Long Term Care. (2009). Family Health Teams: Advancing Family Health 
Care a Guide to Provider Compensation. Toronto: Ontario Ministry of Health and Long Term Care.

Ontario Ministry of Health and Long Term Care. (2009). Family Health Teams: Advancing Family Health Care Guide for Goverance. Toronto: Ontario Ministry of Health and Long Term Care.

Ontario Ministry of Health and Long Term Care. (2009). Guide to Governance and Accountability: Advancing Family Health Teams. Toronto: Ontario Ministry of Health and Long Term Care.

Ontario's Community Health Centres. (2013). Addressing the great health divide. Toronto: Ontario's Community Health Centres.

Department of Health . (2010, Nov). A New Model of Care in Nova Scotia. Retrieved Nov 28, 2014, from http:// novascotia.ca/dhw/mocins/docs/MOCINS-evaluationhighlights.pdf.

Province of Nova Scotia. (2007, Nov 05). Health Team Nova Scotia . Retrieved Nov 23, 2014, from Nova Scotia Health and Wellness: http://www.healthteamnovascotia.ca/ healthcare/structure.html.

Health Canada. (2007, March 1). Primary Health Care Transition Fund. Retrieved Dec 8, 2014, from Health Care System: http://www.hc-sc.gc.ca/hcs-sss/prim/phctffassp/index-eng.php.

Alberta Health, Primary Healthcare Branch. 2014. Strategy Highlights; Primary Healthcare Strategy. Accessed online: http://www.health.alberta.ca/documents/PrimaryHealth-Care-Strategy-Highlights-2014.pdf.

Alberta Medical Association. 2014. Community Engagement for PCNS: A guidebook with tools for developing a community engagement plan.

Nova Scotia Department of Health and Wellness. Collaborative care teams. 2015. Accessed June 15, http:// novascotia.ca/dhw/collaborative-care-teams/

\section{Additional files}

Additional file 1: COREQ. Consolidated Checklist for the Reporting of

Additional file 2: Qualitative Interview Questions. Description of data: Questions used during qualitative interviews. (DOCX 19 kb)

Additional file 3: Qualitative Analysis Tool. Description of data: The framework used to assist with analysis of qualitative interviews. (DOCX $17 \mathrm{~kb}$ )

Additional file 4: Roundtable Agenda. Description of data: Content of discussion during the 2 day research roundtable data collection component. (DOCX $17 \mathrm{~kb})$

\section{Abbreviations}

FFS: Fee for Service; HCP: Health Care Provider; IDPC: Interdisciplinary Primary Care; MD: Medical Doctor; PCN: Primary Care Network

\section{Acknowledgements}

We wish to thank all respondents for the time they took away from their work to participate in the qualitative interviews. We wish to thank all roundtable participants for their dedication to the delivery of interdisciplinary primary care in Canada and the time they took to participate in the roundtable discussions. We thank Katie Harris, Adrian Koops and Helen Hezsely for their assistance with qualitative interviewing, roundtable transcriptions and coding of qualitative data.

\section{Funding}

The study was funded through the Canadian Institutes for Health Research (CIHR) Healthcare Renewal Policy Analysis Grant, funding reference number HRA-126900. The funding body played no role in the design of the study, data collection, analysis, interpretation of the preparation of the manuscript.

\section{Availability of data and materials}

Data will not be shared. Data are in the form of transcripts from qualitative interviews and roundtable discussions. At time of data collection, respondents were assured of confidentiality and anonymization. This process was approved by the relevant research ethics boards. The raw data contains many references to the respondents' particular circumstances that would reveal their identity (e.g. name of clinic, name of town, reference to specific policies, organizations, or historical events). Respondents were promised that their data will be destroyed after the appropriate time period, as per the requirements of research ethics boards. Ethical consent was granted for this particular use of data, and not for secondary / unknown use of data.

\section{Authors' contributions}

DW led the study in all phases (conceptualization, design, ethical approval application, data collection, data analysis, interpretation of results, and preparation of manuscript). DW developed funding applications and obtained study funding. SH was involved in data analysis, interpretation/ discussion of results and preparation of manuscript. AK and $A L$ were involved in study conceptualization and interpretation of results. MK, JE and IB were involved in study conceptualization and facilitation of sampling for qualitative interviews. All authors discussed the progress of the study regularly. All authors reviewed and approved the manuscript.

\section{Authors' information}

DW is an Associate Professor at Dalhousie University. Her areas of expertise are health policy research and health economics. SH is an Adjunct and Research Facilitator at Dalhousie University. She is an expert in qualitative methods. AL is a Professor at Dalhousie University with expertise in epidemiology and health services research. AK is a physician and Director of the Manitoba Centre for Health Policy. At the time of the study, MK was an Executive Director with the Alberta Department of Health, JE was a Regional Director with the Winnipeg Regional Health Authority, and IB was Executive Director with Nova Scotia Department of Health and Wellness.

\section{Competing interests}

The authors declare that they do not have a competing interest. The content of this study is based on academic and grey literature, as well as primary data collected as a part of this study. The results of the study do not express the official position or opinion of the institutions, with whom the authors are affiliated.

\section{Consent for publication}

As a part of the consent form, we described that study findings will be published in academic journals. All participants signed the consent form.

Ethics approval and consent to participate

The study was reviewed and approved by the following Research Ethics Boards:

- Health Research Ethics Board of Alberta-Community Health Committee.

- University of Manitoba-Bannatyne Campus Health Research Ethics Board.

- Capital Health Research Ethics Board (Nova Scotia).

- Colchester East Hants Research Ethics Board (Nova Scotia).

- Guysborough Antigonish Strait Health Authority Research Ethics Board (Nova Scotia).

- Pictou County Health Authority Research Ethics Board (Nova Scotia).

- South Shore Health Ethics Committee (Nova Scotia).

A consent form was prepared and approved by all Research Ethics Boards, and it was signed by all participants. 


\section{Endnote}

n/a.

\section{Publisher's Note}

Springer Nature remains neutral with regard to jurisdictional claims in published maps and institutional affiliations.

\section{Author details}

ISchool of Public Administration, Dalhousie University, Halifax, Canada. ${ }^{2}$ Faculty of Management, Dalhousie University, Halifax, Canada. ${ }^{3}$ Department of Community Health Sciences, Department of Family Medicine, University of Manitoba, Winnipeg, Canada. ${ }^{4}$ Department of Community Health and Epidemiology, Dalhousie University, Halifax, Canada. ${ }^{5}$ Provider Compensation and Strategic Partnership Branch, Alberta Health, Edmonton, Canada. ${ }^{6}$ Primary Health Care and Chronic Disease, Winnipeg Regional Health

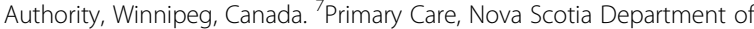
Health and Wellness, Halifax, Canada.

Received: 21 November 2016 Accepted: 4 May 2017

Published online: 15 May 2017

\section{References}

1. Freund T, Everett C, Griffiths P, Hudon C, Naccarella L, Laurant M. Skill mix, roles and remuneration in the primary care workforce: whoa are the healthcare professionals in the primary care teams across the world? Int J Nurs Stud. 2015;52(3):727-43.

2. Khan S, Mcintosh C, Sanmartin C, Watson D, Leeb K. Primary health care teams and their impact on processes and outcomes of care. Ottawa: Statistics Canada; 2008. Available at: www.statcan.gc.ca/pub/82-622-x/82622-×2008002-eng.pdf.

3. Lowe F, O'Hara S. Multi-disciplinary team working in practice: managing the transition. J Interprof Care. 2000;14(3):269-79.

4. Pearson A, Porritt KA, Doran D, Vincent L, Craig D, Tucker D, Long L, Henstidge $\checkmark$. A comprehensive systematic review of evidence on the structure, process and characteristics and composition of nursing teams that foster a healthy work environment. Int J Evid Based Healthc. 2006:4:118-59.

5. Rodriguez HP, Rogers WH, Marshall RE, Safran DG. Multidisciplinary primary care teams: effects on the quality of the clinician-patient interactions and organizational features of care. Med Care. 2007;45(1):19-27.

6. Schuetz B, Mann E, Everett W. Educating health professionals collaboratively for team-based primary care. Health Aff. 2010;29(8):1476-80.

7. Hutchison B, Levesque J-F, Strumpf E, Coyle N. Primary health care in Canada: systems in motion. Milbank Q. 2011:89(2):256-88.

8. Canadian Medical Association. Number and percent distribution of physicians by specialty and sex, Canada 2017. https://www.cma.ca/Assets/ assets-library/document/en/advocacy/06-spec-sex.pdf. Retrieved Nov 2, 2016.

9. National Physician Survey 2013, http://nationalphysiciansurvey.ca/result/ 2013-results-for-family-physicians/ Accessed on 14 Sept 2016

10. Hutchison B, Glazier R. Ontario's primary care reforms have transformed the local care landscape, but a plan is needed for ongoing improvement. Health Aff. 2013;32(4):695-703

11. Strumpf E, Levesque J-F, Coyle N. Innovative and diverse strategies toward primary health care reform: lessons learned from the Canadian experience. J Am Board Fam Med. 2012;25:S27-33.

12. Marchildon GP. Hutchison B. Primary care in Ontario, Canada: New proposals after 15 years of reform. Health Policy. 2016;120(7):732-38.

13. Beckhard R. Organizational issues in the team delivery of comprehensive health care. Milbank Mem Fund Q. 1972;50(3):287-316.

14. Bower P, Campbell S, Bojke C, Sibbald B. Team structure, team climate, and the quality of care in primary care: an observational study. Qual Saf Health Care. 2003;12:273-9

15. Ferrante JM. Balasubramanian BA. Hudson SV. Crabtree BF. Principles of the patient-centered medical home and preventive services delivery. Ann Fam Med. 2010;8(2):108-16.

16. Hogg W, Lemelin J, Dahrouge S, Liddy C, Armstrong CD, Legault F, Dalziel B, Zhang W. Randomized controlled trial of anticipatory and preventive multidisciplinary team care. Can Fam Physician. 2009;12:e78-85.

17. Shaw A, de Lusignan S, Rowlands G. Do primary care professionals work as a team: a qualitative study. J Interprof Care. 2005;19(4):396-405.
18. Proudfoot JG, Bubner T, Amoroso C, Swan E, Holton C, Winstanley J, Beilby J Harris MF. Chronic care team profile: a brief tool to measure the structure and function of chronic care teams in general practice. J Eval Clin Pract. 2009;15:692-8.

19. Wagner $\mathrm{EH}$. The role of patient care teams in chronic disease management. BMJ. 2000;320:569-72.

20. Willens D, Cripps R, Wilson A, Wolff K, Rothman R. Interdisciplinary team care for diabetic patients: primary care physicians, advanced practice nurses, and clinical pharmacists. Clin Diabetes. 2011;29(2):60-7.

21. Farris KB, Cote I, Feeny D, Johnson JA, Tsuyuki RT, Brilliant S, Dieleman S. Enhancing primary care for complex patients: demonstration project using multidisciplinary teams. Can Fam Physician. 2004;50:998-1003.

22. Drew $\mathrm{P}$, Jones $\mathrm{B}$, Norton $\mathrm{D}$. Team effectiveness in primary care networks in Alberta. Healthc Q. 2010;13(3):33-8.

23. Solheim K, Mcelmurry BJ, Kim MJ. Multidisciplinary teamwork in US primary health care. Soc Sci Med. 2007;65:622-34.

24. Deber R, Hollander MJ, Jacobs P. Models of funding and reimbursement in health care: a conceptual framework. Can Public Adm. 2008;51(3):381-405.

25. Cohen S, Bailey D. What makes teams work: group effectiveness research from the shop floor to the executive suite. J Manag. 1997;23(3):239-90.

26. Griffiths J, Austin L, Luker K. Interdisciplinary teamwork in the community rehabilitation of older adults: an example of flexible working in primary care. Prim Health Care Res Dev. 2004:5:228-39.

27. Grumbach K, Bodenheimer T. Can health care teams improve primary care practice? JAMA. 2004;291(10):1246-51.

28. Hurst K, Ford J, Gleeson C. Evaluating self-managed integrated community teams. J Manag Med. 2002;16(6):463-83.

29. Rubin I, Beckhard R. Factors influencing effectiveness of health teams. Milbank Mem Fund Q. 1972;50(3):317-35.

30. Xyrichis A, Lowton K. What fosters or prevents interprofessional teamworking in primary and community care? a literature review. Int J Nurs Stud. 2008:45(1):140-53.

31. West MA, Borrill CS, Dawson JF, Brodbeck F, Shapiro DA, Haward B. Leadership clarity and team innovation in health care. Leadersh Q. 2003; 14:393-410.

32. Chesluk BJ, Holmboe ES. How teams work-or-don't-in primary care: a field study on internal medicine practices. Health Aff. 2010;29(5):874-9.

33. Jansen $\mathrm{L}$. Collaborative and interdisciplinary health care teams: ready or not? J Prof Nurs. 2008;24(4):218-27.

34. Liau CY, Lin CC, Lin YK, Blossom YJL. Partnership disengagement from primary community care networks (PCCNs): a qualitative study for a national demonstration project. BMC Health Serv Res. 2010;10(87):2-8.

35. Long S. Primary health care team workshop: team members' perspectives. J Adv Nurs. 1996;23(5):935-41.

36. Murray S, Silver I, Patel D, Dupuis M, Hayes SM, Davis D. Community group practices in Canada: are they ready to perform their practice? J Contin Educ Health Prof. 2008:28(2):73-8.

37. Ross F, Rink E, Furne A. Integration or pragmatic coalition? an evaluation of nursing teams in primary care. J Interprof Care. 2000:14(3):259-67.

38. Dobson RT, Taylor JG, Henry CJ, Lachaine J, Zello GA, Keegan DL, Forbes DA. Taking the lead: community pharmacists' perception of their role potential within the primary care team. Res Soc Adm Pharm. 2009:5:327-36.

39. McDonald J, Powell Davies G, Jayasuriya R, Fort Harris M. Collaboration across private and public sector primary health care services: benefits, costs and policy implications. J Interprof Care. 2011;25(4):258-64.

40. Pringle D, Horsburgh ME. Interdisciplinary collaboration and primary health care reform. Can J Public Health. 2000;91(2):85-6.

41. Goroll AH, Berenson RA, Schoenbaum SC, Gardner LB. Fundamental reform of payment for adult primary care: comprehensive payment for comprehensive care. J Gen Intern Med. 2007;22(3):410-5.

42. Kiran T, Kopp A, Moineddin R, Glazier RH. Longitudinal evaluation of physician payment reform and team-based care for chronic disease management and prevention. Can Med Assoc J. 2015;187(17):E494-502.

43. Kiran T, Victor JC, Kopp A, Shah BR, Glazier RH. The relationship between primary care models and processes of diabetes care in Ontario. Can J Diabetes. 2012;38(3):172-8.

44. Muldoon L, Dahrouge S, Hogg W, Geneau R, Russell G, Shortt M. Community orientation in primary care practices: results from the comparison of models of primary health care in Ontario study. Can Fam Physician. 2010;56(7):676-83 
45. Russell G, Dahrouge S, Hogg W, Geneau R, Muldoon L, Tuna M. Managing chronic disease in Ontario primary care: the impact of organizational factors. Ann Fam Med. 2009;7(4):309-18.

46. Wranik D, Durier-Copp M. Physician remuneration methods for primary physicians in Canada: expected outcomes and lessons learned. Health Care Anal. 2010;18(1):35-59.

47. Petersen LA, Simpson K, Pietz K, Urech TH, Hysong SJ, Profit J, Conrad DA, Dudley RA, Woodard LD. Effects of individual physician-level and practicelevel financial incentives on hypertension care: a randomized trial. JAMA. 2013;310(10):1042-50.

48. Lin Y, Yin S, Huang J, Du L. Impact of pay for performance on behaviour of primary care physicians and patient outcomes. J Evid Based Med. 2016:9(1):8-23.

49. Allen T, Mason T, Whitaker W. Impacts of pay for performance on the quality of primary care. Risk Manag Healthc Policy. 2014;7:113-20.

50. Gillam SJ, Niroshan Siriwardena A, Steel N. Pay-for-performance in the United Kingdom: impact of the quality and outcomes framework-a systematic review. Ann Fam Med. 2012;10(5):461-8.

51. Scott A, Sivey P, Ait Ouakrim D, Willenberg L, Naccarella L, Furler J, Young D. The effect of financial incentives on the quality of health care provided by primary care physicians. Cochrane Database Syst Rev (online). 2011;9:CD008451

52. Beales J, Walji R, Papoushek C, Austin Z. Exploring professional culture in the context of family health team interprofessional collaboration. Health Int Pract. 2011;1(1):eP1004.

53. Heale R. Overcoming barriers to practice: a nurse practitioner-led model. J Am Acad Nurse Pract. 2012;00:1-6.

54. Kastner M. Tricco AC. Soobiah C. Lillie E. Perrier L. Horsley T. Welch V. Cogo E. Antony J. Straus SE. What is the most appropriate knowledge synthesis method to conduct a review? Protocol for a scoping review. 2012;12:114. doi: 10.1186/1471-2288-12-114.

55. Pope C, Ziebland S, Mays N. Qualitative research in health care: analysing qualitative data. Br Med J. 2000;320:114-6.

56. Corbin J, Strauss A. Basics of qualitative research: techniques and procedures for developing grounded theory. 4th ed. Thousand Oaks: Sage Publications Ltd; 2015.

57. Wendt C, Frisina L, Rothgang H. Healthcare system types: a conceptual framework for comparison. Soc Policy Adm. 2009;43(1):70-90.

58. Gerhard U. The use of Weberian ideal-type methodology in qualitative data interpretation: an outline for ideal-type analysis. Bull Am Meteorol Soc. 1994:45:74-126.

59. Bookey-Bassett S, Markle-Reid M, Mckey CA, Akhtar-Danesh N. Understanding interprofessional collaboration in the context of chronic disease management for older adults living in communities: a concept analysis. J Adv Nurs. 2017;73(1):71-84.

60. Collier D, Laporte J, Seawright J. Putting typologies to work: concept formation, measurement, and analytic rigor. Polit Res Q. 2012;65(1):217-32.

\section{Submit your next manuscript to BioMed Central and we will help you at every step:}

- We accept pre-submission inquiries

- Our selector tool helps you to find the most relevant journal

- We provide round the clock customer support

- Convenient online submission

- Thorough peer review

- Inclusion in PubMed and all major indexing services

- Maximum visibility for your research

Submit your manuscript at www.biomedcentral.com/submit

) Biomed Central 